\title{
The timing of breeding and independence for snow leopard females and their cubs
}

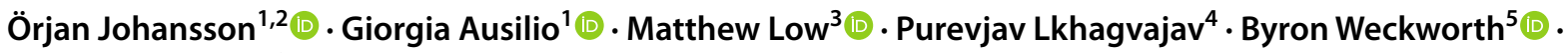 \\ Koustubh Sharma ${ }^{2}$
}

Received: 3 June 2020 / Accepted: 29 September 2020 / Published online: 12 October 2020

(c) The Author(s) 2020

\begin{abstract}
Significant knowledge gaps persist on snow leopard demography and reproductive behavior. From a GPS-collared population in Mongolia, we estimated the timing of mating, parturition and independence. Based on three mother-cub pairs, we describe the separation phase of the cub from its mother as it gains independence. Snow leopards mated from January-March and gave birth from April-June. Cubs remained with their mother until their second winter (20-22 months of age) when cubs started showing movements away from their mother for days at a time. This initiation of independence appeared to coincide with their mother mating with the territorial male. Two female cubs remained in their mothers' territory for several months after initial separation, whereas the male cub quickly dispersed. By comparing the relationship between body size and age of independence across 11 solitary, medium-to-large felid species, it was clear that snow leopards have a delayed timing of separation compared to other species. We suggest this may be related to their mating behavior and the difficulty of the habitat and prey capture for juvenile snow leopards. Our results, while limited, provide empirical estimates for understanding snow leopard ecology and for parameterizing population models.
\end{abstract}

Keywords Age of independence $\cdot$ Life-history trade-offs · Panthera uncia Parental care $\cdot$ Pre-dispersal behavior . Separation $\cdot$ Subadult

Handling editor: Francesco Ferretti.

Electronic supplementary material The online version of this article (https://doi.org/10.1007/s42991-020-00073-3) contains supplementary material, which is available to authorized users.

Örjan Johansson

orjan.johansson@slu.se

1 Grimsö Wildlife Research Station, Swedish University of Agricultural Sciences, Riddarhyttan, Sweden

2 Snow Leopard Trust, Seattle, USA

3 Department of Ecology, Swedish University of Agricultural Sciences, Uppsala, Sweden

4 Snow Leopard Conservation Foundation, Ulaanbaatar, Mongolia

5 Panthera, New York, USA

\section{Introduction}

Parental investment theory postulates that parents should support current offspring if the genetically weighted benefits to the offspring's fitness outweigh the costs to the mother's (Hamilton 1964; Trivers 1972). This is likely to be influenced by many ecological factors, including resource availability (Fuller and Sievert 2001; Kvarnemo et al. 1998; Whittingham and Robertson 1994), mating system and seasonality (Russell et al. 2004; Szekely and Cuthill 2000), social organization (Moehlman 1989; Royle et al. 2012) and the developmental period of the offspring (Olson et al. 2008). Termination of parental care results in increasing separation between the parents and offspring and-unless the offspring take over the parents' home range or settle adjacent to it-ultimately leads to natal dispersal. While dispersal is usually a distinct event (Clobert et al. 2001), the separation period preceding this, where parental care is greatly reduced and juvenile independence increases, is often difficult to clearly define, especially in species where monitoring movements at a relevant spatiotemporal scale 
is difficult (Doerr and Doerr 2005; Samelius et al. 2012). However, with the development of satellite telemetry such as Global Positioning System (GPS)-collars, the tools needed to observe and quantify the separation and dispersal process are available. Despite this, such studies are rare for elusive species because both the mother and offspring must be collared; this requires the offspring to be captured prior to separation, but when old enough to wear a GPS-collar.

Here we present spatiotemporal data collected during the separation phase of three mother-cub pairs in a large, solitary felid: the snow leopard (Panthera uncia). Because of the species' elusive behavior and often inaccessible and rugged mountainous habitat, few data have been recorded on snow leopards' breeding and dispersal behavior. Incidental observations of mating calls and marking behavior suggest that the species has a restricted mating season that occurs between December and March (Hemmer 1972; Jackson and Ahlborn 1988; McCarthy and Chapron 2003; Schaller 1977). Cubs are born the following April-August, and are thought to be dependent on their mother for 1-2 years (Fox and Chundawat 2016; Novikov 1956), or at least for their first winter (Hemmer 1972).

Reliable empirical information regarding the timing of mating, parturition, juvenile independence and the timing of a female's subsequent breeding relative to her current reproductive costs is important for understanding a species' ecology and for modelling their population dynamics and viability (e.g. Rauset et al. 2015; Tarwater and Brawn 2010). To date, there are no published data on these parameters from wild snow leopard populations, thus increasing the value of any available information in this conservation flagship species. We report data from three GPS-collared juvenile snow leopards and their mothers and describe the first stage of independence in this species, i.e. the time of initial separation between juvenile and mother, and the timing of dispersal. We examine the movement patterns of young snow leopards in relation to their mothers and to the core area of their natal range in the months prior to and after separation. Based on these data, we compare snow leopards to other large felids to assess if snow leopards follow the allometric relationship between age of independence and body weight (Gittleman 1986). We also provide estimates for their time of mating and parturition, parameters that are needed for future research on life history, population dynamics, and the general biology of this elusive felid.

\section{Materials and methods}

\section{Study area}

Our study was conducted in the Tost Mountains $\left(43^{\circ} \mathrm{N}\right.$, $100^{\circ} \mathrm{E}$ ), located in the mountain steppe of the southernmost part of Mongolia, between 2010 and 2019. The climate is windy and dry with less than $130 \mathrm{~mm}$ precipitation annually, mean daily temperature ranges from $-14{ }^{\circ} \mathrm{C}$ in January to $23{ }^{\circ} \mathrm{C}$ in July. Tost consists of several rugged mountain massifs (altitude 1600-2500 m above sea level), crossed by steep ravines and separated by wide valleys. Vegetation is sparse and consists mainly of short grasses, dwarf shrubs and patches of shrubs dominated by Amygdalus mongolica, Stipa spp., Caragana leucophlaea and Eurotia ceratoides. The study area $\left(1700 \mathrm{~km}^{2}\right)$ has been surveyed annually since 2009 using camera traps and is estimated to contain 10-14 adult individuals (Sharma et al. 2014). Adult snow leopards display intrasexual territoriality with average home range sizes in Tost of 129 and $220 \mathrm{~km}^{2}$ for adult females and males, respectively (Johansson et al. 2016). The main prey of snow leopards in Tost are Siberian ibex (Capra sibirica) and domestic goat/sheep (Capra hircus/Ovis aries), representing $65 \%$ and $20 \%$ of snow leopard kills, respectively (Johansson et al. 2015). The human population consists of approximately 90 semi-nomadic families who live in the steppe in summer and in the mountains in winter.

\section{Data collection}

Snow leopards were captured in modified Aldrich-style foot-snares and immobilized with a combination of zolazepam-tiletamine and medetomidine (see Johansson et al. 2013 for capture and immobilization details). The snow leopards were fitted with GPS-collars (GPS Plus or Vertex Lite, Vectronic Aerospace, Berlin, Germany) weighing approximately $650 \mathrm{~g}$. Collars were programmed to take a GPS-fix every $5 \mathrm{~h}$ and uplink them via Globalstar or Iridium satellites. All collars were equipped with drop-offs programmed to release after a set time (12-22 months). We collared 26 snow leopards of which 14 were males and 12 were females; of these, 3 were mother-cub pairs where 2 of the cubs were female and 1 was a male. All cubs belonged to different mothers, the two females had no siblings at time of collaring whereas the male had an unmarked sibling. At capture, the cubs were at least 1 year old and weighed $25 \mathrm{~kg}$ (Female 1), $27 \mathrm{~kg}$ (Female 2) and $31 \mathrm{~kg}$ (Male 1). Collars were fitted to the cubs according to the size of an adult cat of respective sex, allowing room for the neck to grow. If a collar was determined as being too loose, e.g. by posing a risk that it could move and get wedged in the mouth, the cub was released uncollared.

We visited the dens of six females on seven occasions when their location patterns around certain dates indicated that they may have given birth. All research was performed following the American Society of Mammalogists guidelines (Sikes et al. 2016), permits to capture snow leopards and conduct research were issued by the Mongolian Ministry of Environment and Tourism. 


\section{Data analyses}

Gestation time in zoos has been reported to be $90-105$ days (Fox and Chundawat 2016) with a mean of 96 days (Blomqvist 2018). There are currently no published studies detailing the mating season or timing of parturition in wild snow leopards. Because snow leopards have a strict mating season it follows that the absolute majority of cubs are born at the same time of the year. Thus, to estimate age of separation in the mother-cub pairs, we calculated the mean parturition date based on seven litters in our study area for which we had accurate date information. From this, we could also estimate the timing of mating in this population by subtracting the known mean gestation time of 96 days from the parturition dates.

Natal home ranges of the collared cubs were calculated based on the mothers' GPS locations and estimated as 95\% Minimum Convex Polygons (MCP) in the software R (R Development Core Team 2019) using the package Adehabitat (Calenge 2006). Since data were collected at different times from each collar, we used the $\mathrm{R}$ package moveVis (Schwalb-Willmann et al. 2020) to create a continuous dataset with a temporal resolution of $5 \mathrm{~h}$, thus predicting the most likely location of animals at the same time stamps. We then estimated the Cartesian distance between the mother-juvenile pair at each timestamp. We plotted the absolute distance between individuals at a resolution of $5 \mathrm{~h}$ and the moving average of distance between individuals over the past $50 \mathrm{~h}$. We arbitrarily define separation to occur, and age of independence to begin, when the average distance between a cub and mother was more than $1000 \mathrm{~m}$ for at least $48 \mathrm{~h}$. We also identified the arithmetic mean of the mother's home range, and calculated the distance between the arithmetic mean and all the GPS positions of both mother and cub using ArcGIS (Environmental Systems Research Institute, Redlands, California). Combined, this allowed us to examine: (1) when cubs showed evidence of separation from their mothers; (2) how long the separation phase lasted; and (3) if the cubs remained within the natal range during the entire separation phase or ventured outside of this area. The separation phase was defined to last from age of independence until (1) the cub left the natal range permanently, i.e. performed a natal dispersal or; (2) the first reproduction event for those cubs that did not disperse. The latter is a form of passive parental care as the mother defends the territory that the cub utilizes (Class and Moore 2010; Royle et al. 2012).

\section{Comparison with other felids}

To compare the snow leopard to other felids in relation to the allometric relationship between age of independence and body weight, we compared our estimates to felids with an average body weight $\geq 10 \mathrm{~kg}$ for which we could find estimates in the literature; these were the jaguar (Panthera onca), puma (Puma concolor), cheetah (Acinonyx jubatus), tiger (Panthera tigris), leopard (Panthera pardus), Eurasian lynx (Lynx lynx), Canadian lynx (Lynx canadensis), bobcat (Lynx rufus), caracal (Caracal caracal) and serval (Leptailurus serval). We obtained weights for females and males of each species, which we then averaged into one value for each species. The average weight was then $\log (e)$ transformed to be used as our final weight variable. Age of independence was usually reported as a range in the literature, so we calculated a mean for each species and used that as our age of independence variable. We analyzed the data using a linear model in R from the package stats (R Core Team 2013), with age of separation as our response variable and $\log$ (weight) as our predictor. We standardized the residuals of the linear model to identify any potential outliers (standardized residual $>1.96$ ) among the species.

\section{Results}

Parturition for the seven known litters occurred between April 29 and June 28 (mean date: May 30, median date: June 1 ), indicating that mating took place (assuming a 96-day gestation) between January 23 and March 24 (mean date: February 23, median date: February 25). Based on this, we used a mean parturition date of June $1 \pm 1$ month when estimating the age of independence.

\section{Female 1 separation}

Separation began on January 19, 2011, and lasted at least 129 days, until May 27 when the drop-off released the collar as programmed (Figs. 1, 2). Female 1's age at beginning of separation was estimated to be $20( \pm 1)$ months. During the 129 days, Female 1 left her natal range on five different exploratory forays. Each time she returned within her natal range, she reunited with her mother and they remained together for 4, 1, 16 and 3 days, respectively (Fig. 2). During her last exploratory foray, her mother gave birth to a new litter 3 days before Female 1 reunited with her at the den site. The farthest she was documented from the centroid of her natal range was $56 \mathrm{~km}$. After dropping the collar, Female 1 was neither seen on camera traps nor collared again; she had not dispersed at $24 \pm 1$ months age although her fate is currently unknown.

\section{Female 2 separation}

Separation began on February 10, 2019, when Female 2 was $21( \pm 1)$ months old, and lasted at least 215 days until September 13, after which her collar ceased working (Figs. 1, 2). During these 215 days, Female 2 left her natal range 


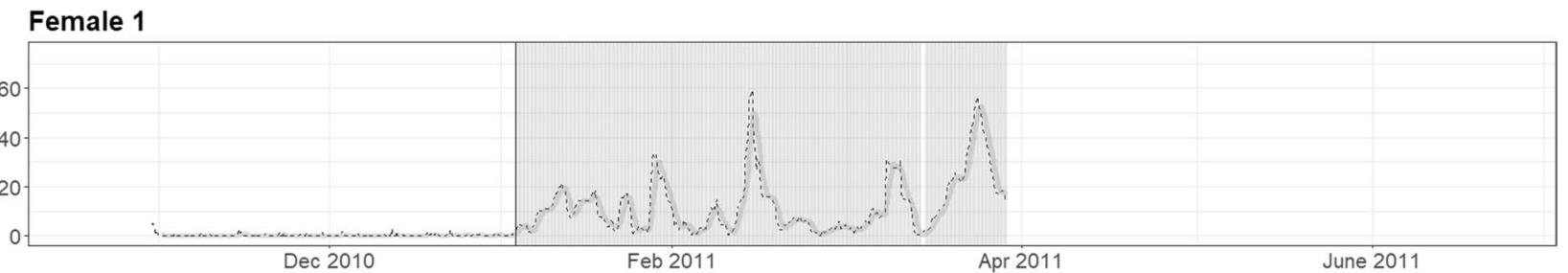

Female 2

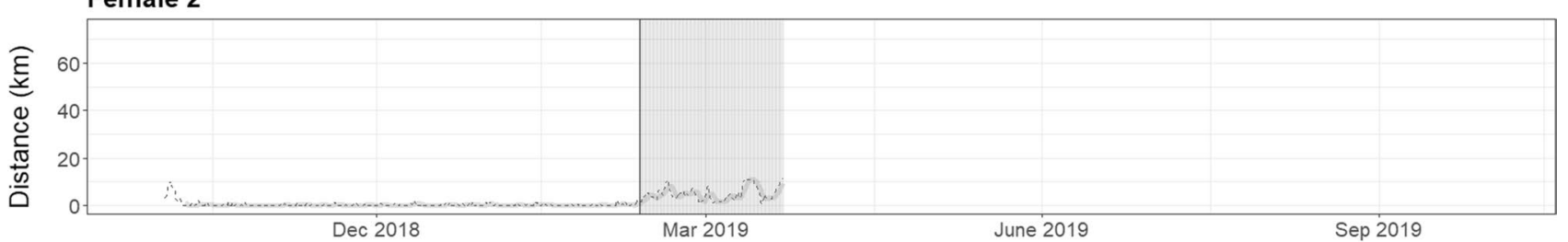

Male 1

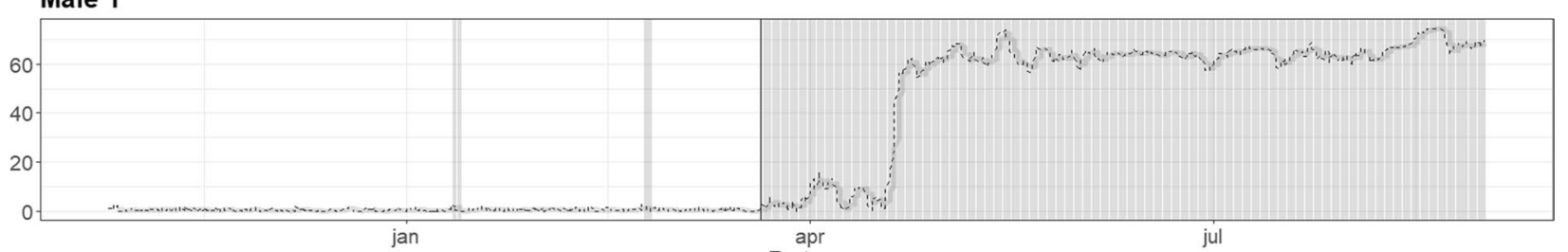

Date

Fig. 1 The distance between GPS locations for three collared snow leopard females and cubs in Tost Mountains, Mongolia. The dashed lines show actual values and the solid lines show a 3-day moving average of distances. Black vertical lines indicate dates when inde- pendence of cubs occurred (i.e. $>1000 \mathrm{~m}$ separation for more than $48 \mathrm{~h}$ ); shaded areas show when cubs were separated from their mothers by $1000 \mathrm{~m}$ or more
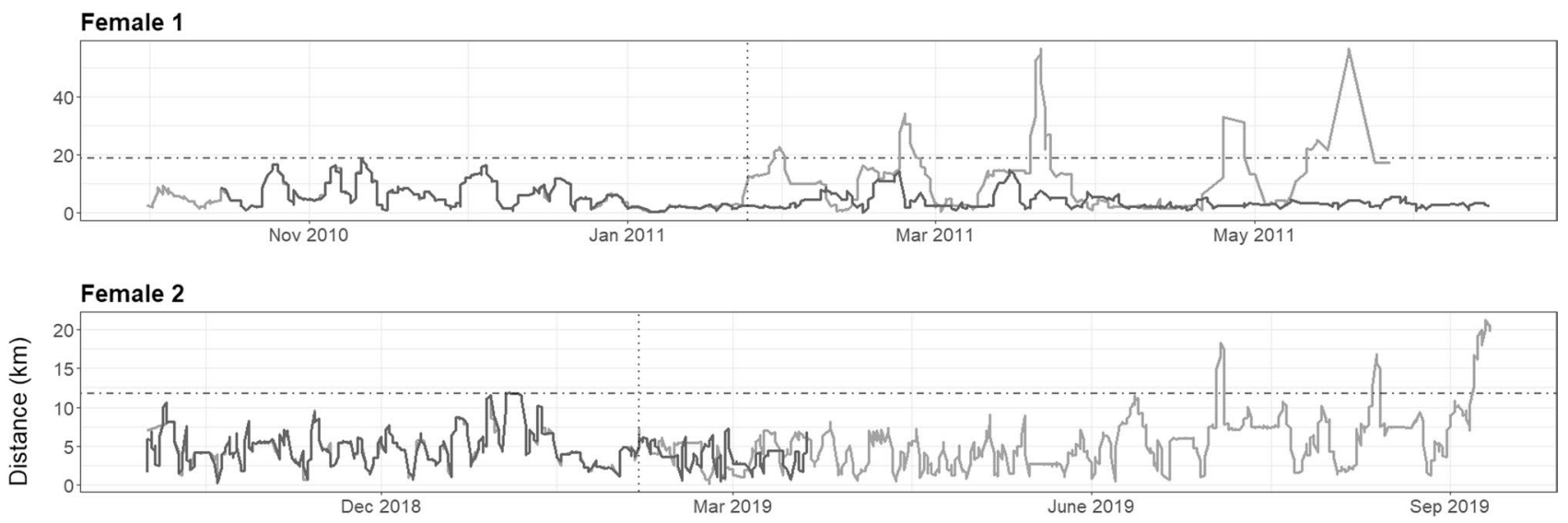

Male 1

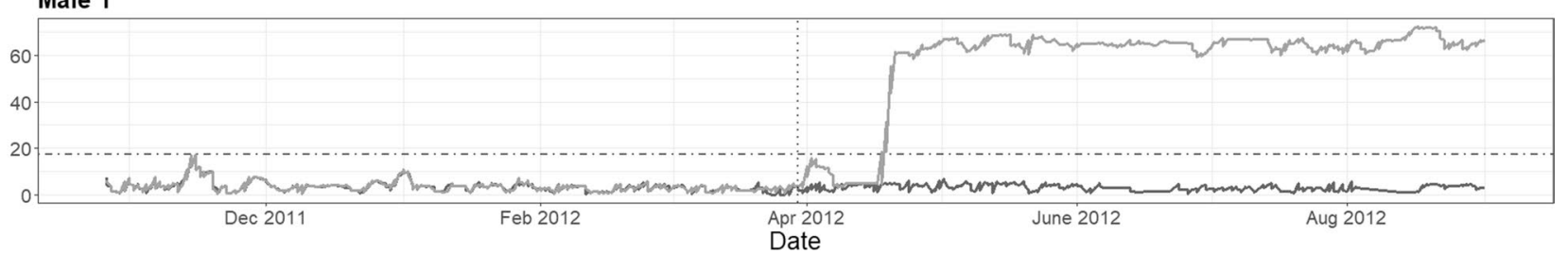

Fig. 2 The distance between the centroid of the natal range and the location for three GPS-collared snow leopard females (dark-grey lines) and cubs (light-grey lines) in Tost Mountains, Mongolia. The dashed vertical line marks the separation (age of independence) between the mothers and their cubs. The dashed horizontal line marks the border furthest from the centroid, i.e. any location further away from the centroid is outside of the natal range 
on three exploratory forays, lasting 2, 4 and at least 6 days respectively; during the last of these her collar malfunctioned (Fig. 2). The first time she left her natal range was on July 4, 142 days after separating from her mother for the first time. We could not monitor her mother's movements after March 21 because her collar malfunctioned. During the 29 days between separation and collar failure, Female 2 reunited with her mother twice, 18 and 26 days after separation had occurred. On both occasions, they remained together for a single day (Fig. 2). Female 2 was subsequently photographed by trap-cameras in her natal range at eight occasions in October through December 2019. In February 2020 we received VHF-signals from her collar in the central parts of her natal range, showing that she had not dispersed at the age of $33( \pm 1)$ months. Her mother remained in the same area and in November 2019 a trap-camera photographed her and three cubs, born in 2019.

\section{Male 1 separation}

Separation began on March 21, 2012, and lasted 30 days until April 20, when he was $22( \pm 1)$ months old (Figs. 1, 2). Prior to independence, Male 1 parted from his mother on two occasions, on January 12-13 and February 24-25, both of them lasting less than $48 \mathrm{~h}$. Eight days after the first separation event, the male reunited with his mother and remained together with her for 2 days. In the last 12 days preceding dispersal, Male 1 remained within $3 \mathrm{~km}$ from his mother; during this time, they were likely together three times on single locations (distance between locations 74, 39 and $97 \mathrm{~m}$ ). The last encounter occurred when the mother had killed an adult ibex, immediately thereafter, Male 1 permanently left

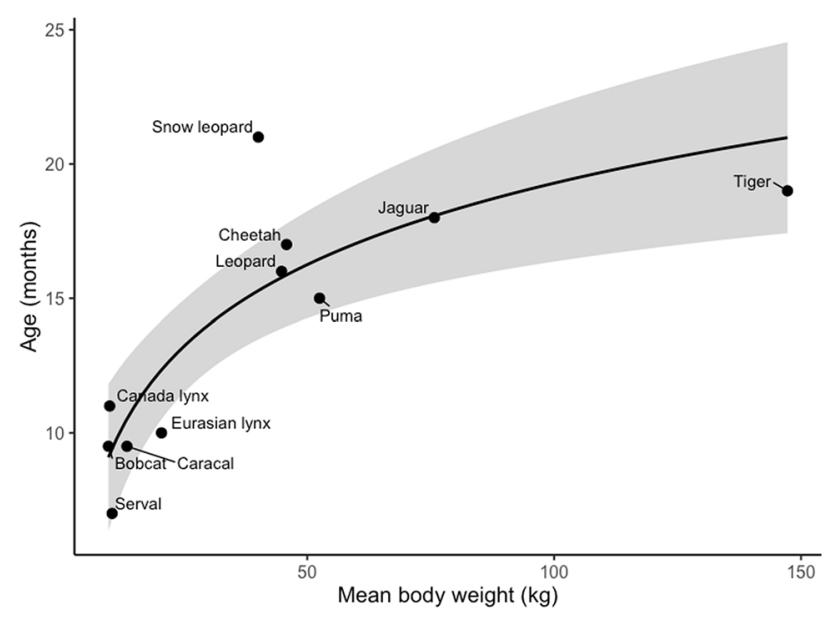

Fig. 3 The relationship between mean body weight and age of independence in medium-sized and large solitary felids. The line is derived from a linear model with body-weight $\log (e)$ transformed $\left(\beta=4.38, \mathrm{SE}=0.86, R^{2} 0.74\right)$; shaded areas show the $95 \%$ confidence intervals his natal range and dispersed to a neighboring mountain range $77 \mathrm{~km}$ away at the age of $23 \pm 1$ months (Fig. 2).

\section{Comparison with other felids}

The average weight of snow leopards is $40 \mathrm{~kg}$ (Johansson et al. 2015) and this study found age of independence beginning at around 21 months of age. For 10 other felid species that we could find information for (Online Resource 1), weight strongly affected age of separation at the logarithmic scale $\left(\beta=4.38 \pm 0.86(\mathrm{SE}), R^{2}=0.74\right)$; thus heavier felid species reach independence much later in life than smaller felids (Fig. 3). The snow leopard, however, appears to be an outlier ( standardized residual $=2.42$ ), being the smallest 'large cat', yet reaching independence later than all other species in our comparison (Fig. 3).

\section{Discussion}

Here we show that snow leopard cubs stay with their mothers for an extended period of time and do not display initial separation behaviors until they were 20-22 months old. There was little variation in the age when independence was initiated, but the age of dispersal (or possible dispersal) showed more variation (from 23 to $\geq 33$ months). The cause of the initial separation behavior was likely their mother mating, as both Female 1 and Male 1 first showed behavioral separation when their mothers were together with territorial adult males (both collared). Female 2 initiated separation when her mother remained in the same small area for 3 days, which is a behavioral pattern typical of mating (the territorial male in the area was not collared at the time). This suggests that snow leopard cubs begin independence during the mating season in their second winter and that separation between mother and cub may be triggered by the presence of an adult male or a change in their mother's tolerance of their presence as she prepares to breed again.

The male cub dispersed about a month after initial separation from his mother, whereas the GPS-collar data show that the separation phase continued for at least four and seven months for the two female cubs, after which we do not know if and when the cubs dispersed outside their natal ranges. During the time the collars worked, both females conducted exploratory forays, indicating that they had not become residents in their natal ranges. Camera-trap photographs and VHF-signals from Female 2's collar shows that she had not dispersed from her natal range until at least 12 months after separation. Assuming a sex difference in the length of the separation phase actually exists, this could be explained by different adult tolerances towards male versus female cubs. Adult territorial males would be expected to be more tolerant towards female cubs in their range, than towards a male 
cub approaching independence and maturity. Similarly, adult females may be more tolerant to female cubs post-independence. The last time Male 1 reunited with his mother was a single GPS location the day after she had killed an adult ibex. The mother remained at the kill-site for three more days after Male 1 left, indicating that there was plenty of food left and that she would not allow him to feed on the kill. The same pattern has been documented in leopards where mothers aggressively rebutted independent cubs trying to get access to their kills (Balme et al. 2017). In contrast, snow leopard females regularly share kills with adult daughters and their cubs (Snow Leopard Trust, unpublished data). Territorial species like large felids generally display sex-biased dispersal, where female offspring regularly establish home ranges that overlap with their mothers (e.g. Gour et al. 2013; Samelius et al. 2012; Smith 1993). This philopatric behavior suggests both that adult females are more tolerant towards female offspring post-independence, perhaps making it more difficult to discern spatial signals of when separation phase ends, and that, on average, there is a much shorter separation phase in male cubs compared to females.

The median date of mating (February 25) and parturition (June 1) in our dataset falls within the range suggested in the literature (e.g. Jackson and Ahlborn 1988; McCarthy and Chapron 2003; Schaller 1977). To validate their accuracy, we compared our dates of parturition with dates reported for captive snow leopards in zoos. Almost half of 1292 captive births in the Northern hemisphere (48\%) occurred throughout May with another 18\% in April and 20\% in June (Blomqvist 2018), which coincides with our estimates. In zoo enclosures, the animals do not have to locate a suitable partner to mate with, which could explain the slightly earlier parturition date. As far as we know, ours are the first published data on mating and parturition dates for snow leopards in the wild.

Our findings suggest that snow leopards are outliers compared to other felids when considering how body weight relates to the age of independence (Gittleman 1986; Fig. 3). Snow leopard cubs reach independence at a later age than all solitary felids, despite being among the smallest of the large cats. One difference between snow leopards and other large felids is that snow leopards appear to have a short mating season (January-March), while other large felids have the potential for multiple estrous events throughout the year (Brown 2011; Graham et al. 1995; Jewgenow et al. 2014). Consequently, reproduction in snow leopards can only occur within a clearly defined 12-month cycle. Apparently, the cubs are not developed enough to be independent at the age of 12 months, leading to a minimum interbirth interval of 24 months. Thus, even if snow leopard cubs were fully developed at a younger age than our separation data suggest, the lack of breeding opportunity for their mother before their second winter could direct her to extend the parental care by allowing the cubs to remain, improving inclusive fitness. In contrast, for other large felids whose mating season is not as constrained as the snow leopards, a reduction in the duration of parental care could potentially reduce the time to next reproductive opportunity. However, in leopards that can reproduce throughout the year, the average interbirth interval was 24 months, which is the same as what is plausible for a snow leopard, even so the leopard cubs reached independence at 18 months age (Balme et al. 2017). Because providing food for large cubs requires a substantial investment by the mother (a puma female with large cubs can have three to four times higher energetic needs than a female without cubs; Ackerman et al. 1986; Laundré 2005), once the cubs no longer require her direct care separation should follow. This pattern appears in our data: at 20-22 months of age when the cubs have developed enough and are no longer dependent, the mother mates again and separation begins.

A second factor influencing the age of separation and independence in felids is the age at which animals are able to successfully hunt on their own. The development of hunting skills and permanent teeth in felids appears to dictate the minimum age of independence of young (e.g. Elbroch and Quigley 2013; Chundawat 2018). In this respect, the larger the average prey species, the more time is needed for cubs to learn successful hunting techniques (Kitchener 1999), hence the allometric relationship between body size and age of independence (since bigger cats usually hunt bigger prey). While most solitary large felids prefer prey similar to their own size or smaller (e.g. Hayward et al. 2006, 2012), snow leopards predominantly hunt ibex, blue sheep (Pseudois nayaur) and Himalayan Tahr (Hemitragus jemlahicus) (Lovari et al. 2013; Lyngdoh et al. 2014), which are considerably heavier (mean weight $55 \mathrm{~kg}$; Lyngdoh et al. 2014) than snow leopards (mean weight $40 \mathrm{~kg}$; Johansson et al. 2015). Because of the mountainous habitat occupied by the species and the large prey relative to predator size, opportunities for snow leopard mothers to release large prey for the cubs to successfully practice killing is rare (e.g. in contrast to cheetahs; Caro 1994, and tigers; Chundawat 2018). Thus, there are likely a number of factors that result in snow leopard independence being at a later age than would be predicted by bodyweight alone.

While our sample size is limited, these are the first detailed data on life history parameters for wild snow leopards. Once an animal has reached independence, it needs to find a home range to settle in, be it through dispersal or by acquiring parts or all of the natal range. Because snow leopard cubs seem to reach independence so late in life and this occurs during the mating season in their second winter, it is highly unlikely that they will have their first litter before 3 years of age. The late age of independence also shows that the minimum inter-birth interval for successful litters is two 
full years. This information is a valuable addition to more precise population modelling for conservation purposes such as IUCN threat assessments (McCarthy et al. 2017).

Acknowledgements We are thankful to the Ministry for Environment and Green Development, Government of Mongolia, and the Mongolian Academy of Sciences for supporting our work. We are thankful to the Disney Conservation Fund, David Shepherd Wildlife Foundation, Columbus Zoo and Aquarium, Snow Leopard Trust UK and Edrington group, Fondation Segré and the Whitley Fund for Nature for their support. Comments on earlier versions of the manuscript from G. Samelius, S. Lovari and one anonymous reviewer improved it greatly.

Author contributions ÖJ, GA and KS conceived the ideas and designed the experiment; ÖJ, PL and KS collected the data; GA, KS and ÖJ analysed the data; ÖJ, GA and ML led the writing of the manuscript. All authors contributed critically to the drafts and gave final approval for publication.

Funding Open access funding provided by Swedish University of Agricultural Sciences. The research was supported by the Snow Leopard Trust, Swedish University of Agricultural Sciences and Panthera. ML was supported by the Swedish Research Council VR (Grant no. VR-2013-3634).

Availability of data and material The GPS data from the collared snow leopards are sensitive. We will not make the data available as it can be used to determine frequently used travel paths and resting sites

\section{Compliance with ethical standards}

Conflict of interest On behalf of all authors, the corresponding author states that there is no conflict of interest.

Ethics approval We obtained the relevant permit from Mongolia's Ministry for Environment and Green Development to allow us to conduct research, capture and collar snow leopards in our study area. All animal handling followed the appropriate ethical standards.

Open Access This article is licensed under a Creative Commons Attribution 4.0 International License, which permits use, sharing, adaptation, distribution and reproduction in any medium or format, as long as you give appropriate credit to the original author(s) and the source, provide a link to the Creative Commons licence, and indicate if changes were made. The images or other third party material in this article are included in the article's Creative Commons licence, unless indicated otherwise in a credit line to the material. If material is not included in the article's Creative Commons licence and your intended use is not permitted by statutory regulation or exceeds the permitted use, you will need to obtain permission directly from the copyright holder. To view a copy of this licence, visit http://creativecommons.org/licenses/by/4.0/.

\section{References}

Ackerman B, Lindzey F, Hemker T (1986) Predictive energetics model for cougars. In: Miller SD, Everett DD (eds) Cats of the world: biology, conservation, and management. National Wildlife Federation, Washington, DC, pp 333-352

Balme GA, Robinson HS, Pitman RT, Hunter LTB (2017) Flexibility in the duration of parental care: female leopards prioritise cub survival over reproductive output. J Anim Ecol 86:1224-1234. https://doi.org/10.1111/1365-2656.12713

Blomqvist L (2018) International pedigree book for snow leopards, Panthera uncia. vol 11. Nordens Ark Foundation

Brown JL (2011) Female reproductive cycles of wild female felids. Anim Reprod Sci 124:155-162

Calenge C (2006) The package "adehabitat" for the R software: a tool for the analysis of space and habitat use by animals. Ecol Model 197:516-519

Caro T (1994) Cheetahs of the Serengeti Plains: group living in an asocial species. University of Chicago Press, Chicago

Chundawat RS (2018) The rise and fall of the emerald tigers: ten years of research in Panna National Park. Speaking Tiger Publishing Pvt Limited, New Delhi

Class A, Moore I (2010) Is there a trade-off between caring for offspring and territorial aggression in tropical male rufous-collared sparrows (Zonotrichia capensis)? Behaviour 147:1819-1839. https://doi.org/10.1163/000579510x538296

Clobert J, Danchin E, Dhondt AA, Nichols J (2001) Dispersal. Oxford University Press, Oxford

Doerr ED, Doerr VA (2005) Dispersal range analysis: quantifying individual variation in dispersal behaviour. Oecologia 142:1-10. https ://doi.org/10.1007/s00442-004-1707-z

Elbroch LM, Quigley H (2013) Observations of wild cougar (Puma concolor) kittens with live prey: implications for learning and survival. Can Field-Natural 126:333-335

Fox JL, Chundawat RS (2016) What is a snow leopard? Behavior and ecology. In: McCarthy T, Mallon DP (eds) Snow leopards. vol Biodiversity of the world. Elsevier, Amsterdam, pp 13-21

Fuller TKS, Sievert PR (2001) Carnivore demography and the consequences of changes in prey availability. In: MacDonald SM, Wayne DRK, Gittleman JLF (eds) Carnivore conservation. Cambridge University Press, Cambridge, pp 163-178

Gittleman JL (1986) Carnivore life history patterns: allometric, phylogenetic, and ecological associations. Am Nat 127:744-771

Gour DS et al (2013) Philopatry and dispersal patterns in tiger (Panthera tigris). PLoS ONE 8:e66956. https://doi.org/10.1371/journ al.pone. 0066956

Graham L, Goodrowe K, Raeside J, Liptrap R (1995) Non-invasive monitoring of ovarian function in several felid species by measurement of fecal estradiol-17 $\beta$ and progestins. Zoo Biol 14:223-237

Hamilton WD (1964) The genetical evolution of social behaviour II. J Theor Biol 7:17-52

Hayward MW, Henschel P, O’Brien J, Hofmeyr M, Balme G, Kerley GIH (2006) Prey preferences of the leopard (Panthera pardus). J Zool 270:298-313. https://doi.org/10.111 1/j.1469-7998.2006.00139.x

Hayward MW, Jędrzejewski W, Jêdrzejewska B, Kitchener A (2012) Prey preferences of the tiger Panthera tigris. J Zool 286:221-231. https://doi.org/10.1111/j.1469-7998.2011.00871.x

Hemmer H (1972) Uncia uncia. Mamm Species 1972:1-5

Jackson R, Ahlborn G (1988) Observations on the ecology of snow leopard in west Nepal. In: Freeman H (ed) Fifth International snow leopard symposium, Seattle, Washington. Snow Leopard Trust, pp 65-87

Jewgenow K, Painer J, Amelkina O, Dehnhard M, Goeritz F (2014) Lynx reproduction-long-lasting life cycle of corpora lutea in a feline species. Reprod Biol 14:83-88. https://doi.org/10.1016/j. repbio.2014.03.002

Johansson Ö, Malmsten J, Mishra C, Lkhagvajav P, McCarthy T (2013) Reversible immobilization of free-ranging Snow Leopards (Panthera uncia) with a combination of medetomidine and tiletamine-zolazepam. J Wildl Dis 49:338-346

Johansson Ö, McCarthy T, Samelius G, Andrén H, Tumursukh L, Mishra C (2015) Snow leopard predation in a livestock dominated landscape in Mongolia. Biol Cons 184:251-258 
Johansson Ö, Rauset GR, Samelius G, McCarthy T, Andrén H, Tumursukh L, Mishra C (2016) Land sharing is essential for snow leopard conservation. Biol Cons 203:1-7

Kitchener AC (1999) Watch with mother: a review of social learning in the Felidae. In: Box HO, Gibson KR (eds) Mammalian social learning: Comparitive and ecological processes. Cambridge University Press, Cambridge, pp 236-258

Kvarnemo CS, Forsgren OE (1998) Parental behaviour in relation to food availability in the common goby. Anim Behaviour $56: 1285-1290$

Laundré JW (2005) Puma energetics: a recalculation. J Wildl Manag 69:723-732

Lovari S, Minder I, Ferretti F, Mucci N, Randi E, Pellizzi B (2013) Common and snow leopards share prey, but not habitats: competition avoidance by large predators? J Zool 291:127-135. https ://doi.org/10.1111/jzo.12053

Lyngdoh S, Shrotriya S, Goyal SP, Clements H, Hayward MW, Habib B (2014) Prey preferences of the snow leopard (Panthera uncia): regional diet specificity holds global significance for conservation. PLoS ONE 9:e88349. https://doi.org/10.1371/ journal.pone.0088349

McCarthy TM, Chapron G (2003) Snow leopard survival strategy. In: Snow leopard trust and snow leopard network, Seattle, Washington

McCarthy T, Mallon D, Jackson R, Zahler P, McCarthy K (2017) Panthera uncia. The IUCN red list of threatened species 2017:e. T22732A50664030. https://doi.org/10.2305/IUCN.UK.2017-2. RLTS.T22732A50664030.en

Moehlman PD (1989) Intraspecific variation in canid social systems. In: Carnivore behavior, ecology, and evolution. Springer, pp 143-163

Novikov G (1956) Carnivorous mammals of the fauna of the USSR (English translation. 1962. Israel program for scientific translations). In: Moskva-Leningrad: Izdatel stvo Akademii Nauk SSSR. Moscow, Russia

Olson VA, Liker A, Freckleton RP, Szekely T (2008) Parental conflict in birds: comparative analyses of offspring development, ecology and mating opportunities. Proc Biol Sci 275:301-307. https://doi.org/10.1098/rspb.2007.1395

R Core Team (2013) R package stats: a language and environment for statistical computing $\mathrm{R}$ foundation for statistical computing, Vienna, Austria

R Development Core Team R (2019) R: A language and environment for statistical computing. R foundation for statistical computing Vienna, Austria

Rauset GR, Low M, Persson J (2015) Reproductive patterns result from age-related sensitivity to resources and reproductive costs in a mammalian carnivore. Ecology 96:3153-3164
Royle NJ, Smiseth PT, Kölliker M (2012) The evolution of parental care. Oxford University Press, Oxford

Russell EM, Yom-Tov Y, Geffen E (2004) Extended parental care and delayed dispersal: northern, tropical, and southern passerines compared. Behavioral Ecol 15:831-838. https://doi.org/10.1093/ beheco/arh088

Samelius G et al (2012) Spatial and temporal variation in natal dispersal by Eurasian lynx in Scandinavia. J Zool 286:120-130. https:// doi.org/10.1111/j.1469-7998.2011.00857.x

Schaller GB (1977) Mountain monarchs. Wild sheep and goats of the Himalaya. University of Chicago Press, Chicago

Schwalb-Willmann J, Remelgado R, Safi K, Wegmann M, Graham L (2020) moveVis: animating movement trajectories in synchronicity with static or temporally dynamic environmental data in R. Methods Ecol Evol. https://doi.org/10.1111/2041-210x.13374

Sharma K, Bayrakcismith R, Tumursukh L, Johansson O, Sevger P, McCarthy T, Mishra C (2014) Vigorous dynamics underlie a stable population of the endangered snow leopard Panthera uncia in Tost Mountains, South Gobi, Mongolia. PLoS ONE 9:e101319. https://doi.org/10.1371/journal.pone.0101319

Sikes RS, Animal C, Use Committee of the American Society of M (2016) Guidelines of the American Society of Mammalogists for the use of wild mammals in research and education. J Mammal 97:663-688. https://doi.org/10.1093/jmammal/gyw078

Smith JLD (1993) The role of dispersal in structuring the Chitwan tiger population. Behaviour 124:165-195

Szekely T, Cuthill IC (2000) Trade-off between mating opportunities and parental care: brood desertion by female Kentish plovers. Proc Biol Sci 267:2087-2092. https://doi.org/10.1098/rspb.2000.1253

Tarwater CE, Brawn JD (2010) The post-fledging period in a tropical bird: patterns of parental care and survival. J Avian Biol 41:479_ 487. https://doi.org/10.1111/j.1600-048X.2010.05006.x

Trivers RL (1972) Parental investment and sexual selection. In: Campbell BC (ed) Sexual selection and the descent of man. Aldine, Chicago, pp 1871-1971

Whittingham LAR, Robertson RJ (1994) Food availability, parental care and male mating success in red-winged blackbirds (Agelaius phoeniceus). J Anim Ecol 63:139-150

Publisher's Note Springer Nature remains neutral with regard to jurisdictional claims in published maps and institutional affiliations. 